\title{
DOAÇÃO COMPARTILHADA DE OÓCITOS SOB OS ASPECTOS DO DIREITO E DA BIOÉTICA
}

\author{
SHARED DONATION OF OOCYTES ON THE ASPECTS OF THE LAW AND BIOETHICS
}

\author{
Ana Virgínia Gabrich Fonseca Freire Ramos ${ }^{110}$ \\ Débora Soares Couto ${ }^{111}$
}

Artigo recebido em: 04/12/2018.

Artigo aprovado em: 17/12/2018.

Resumo: O teor desta pesquisa consiste no estudo de uma das técnicas de reprodução humana assistida (RA), qual seja a Doação Compartilhada de Oócitos. As técnicas de RA visam permitir que mulheres com dificuldade para engravidar tenham a gestação. Ressalta-se que o resultado almejado nem sempre será alcançado, podendo ocorrer tentativas infrutíferas. No desenvolvimento dos capítulos, serão abordadas algumas das técnicas existentes, a questão da diminuição da fertilidade feminina devido ao envelhecimento, a relação negocial entre os envolvidos nesta doação e o elo dessa prática médica com a bioética.

Palavras chaves: Reprodução Humana Assistida; Doação Compartilhada de Oócitos; Direito; Bioética.

Abstract: The content of this research consists in the study of one of the assisted reproduction's techniques, which is Egg Sharing. The techniques aim to allow women with difficulty to conceive in being able to gestate. It is emphasized that the intended result is not always achieved, unsuccessful attempts may occur. Along with the development of chapters, some of the existing techniques be addressed, also the issue of female fertility decline due to aging, the negotiation aspect of the relationship between those involved in this donation and the link between this medical practice and bioethics.

Keywords: Assisted Human Reproduction; Egg Sharing; Law; Bioethics.

\section{INTRODUÇÃO}

As inovações tecnológicas consistem em conhecimentos técnicos e científicos que abrem um amplo caminho para a solução de questões até então não respondidas ou o aperfeiçoamento dos mecanismos já empregados, tornando-os mais eficientes. O presente trabalho é direcionado à tecnologia no âmbito da medicina.

\footnotetext{
${ }^{110}$ Mestre em Direito pela Escola Superior Dom Helder Câmara (DHC); Especialista em Direito Ambiental pela Universidade Gama Filho; Bacharel em Direito pela PUC Minas; Professora da DHC

111 Graduanda em Direito pela Escola Superior Dom Helder Câmara (DHC); Integrante do Grupo de Iniciação Científica Autonomia Privada no exercício de situações jurídicas que envolvam e bioética e o biodireito, da DHC.
} 
Nesse contexto, uma grande conquista no campo da saúde foi a invenção da fertilização in vitro, descoberta por Robert Edwards. Edwards iniciou suas pesquisas na década de 1950, estudando o desenvolvimento de embriões em ratos, período no qual percebeu que seus estudos poderiam influir na busca pela fertilidade.

A partir de então, a conquista empreendida por esse biólogo e pesquisador resultou na primeira criança, Louise Joy Brown, a nascer por meio da técnica de fertilização in vitro, na Grã-Bretanha, em 1978, fator que justificou a entrega do prêmio Nobel de Medicina e Fisiologia a Robert Edwards em 2010. (G1, 2010).

As técnicas de fertilização in vitro foram se desenvolvendo ao longo dos anos, sendo possível se falar na Doação Compartilhada de Oócitos. Tal hipótese ocorre sempre que doadora e receptora, já em tratamento devido à problemas de reprodução, compartilham tanto do material biológico quanto dos custos financeiros necessários para a realização do procedimento de Reprodução Humana Assitida (RA).

A possibilidade não possui regulamentação legal, mas está prevista na Resolução do Conselho Federal de Medicina de $n^{\circ}$ 2.168/2017, que estabelece as normas técnicas de reprodução assistida. Além da previsão da Doação Compartilhada, a Resolução estabelece que a doação não pode ter caráter lucrativo ou comercial, bem como que as doadoras não podem conhecer a identidade das receptoras e vice-versa.

Apesar da previsão da Resolução, o que se pretende constatar com essa pesquisa é se, na prática, existe ou inexiste a comercialização na Doação Compartilhada de Oócitos; qual é a relação negocial existente entre a clínica e as mulheres que se submetem a essa reprodução assistida e entre a doadora e a receptora, bem como a aplicação de princípio da beneficência nessa modalidade de reprodução.

É a partir dessas inquietações que o presente artigo se desenvolve. Buscando sempre enfatizar seu caráter transdisciplinar, a pesquisa tem como base dados secundários, extraídos principalmente de livros e artigos científicos sobre o tema.

A metodologia utilizada, de acordo com o objetivo geral, é a pesquisa exploratória apoiada em levantamento bibliográfico, tendo em vista a intenção de se proporcionar maior familiaridade com os problemas apontados, tornando-os mais explícitos. Com relação ao método, utilaza-se o hipotético-dedutivo.

O objetivo geral do artigo é analisar a relação negocial existente na Doação Compartilhada de Óocitos. Para tanto, são utilizadas fontes da medicina, biologia, filosofia e do direito, a fim de construir uma argumentação lógico-jurídica consistente.

O problema do artigo está centrado na relação entre doadora e receptora e entre estas e a clínica. Haveria, na prática, algum tipo de relação negocial entre doadora e receptora? E entre elas a cliníncia de reprodução assistida?

A justificativa se dá, além de todas as razões acima expostas, pela importância das questões postas em debate, principalmente considerando-se que atualmente a mulheres engravidam mais tardiamente, o que 
leva a um aumento na procura por procedimentos de RA, além do aumento dos problemas de fertilidade dos casais.

O texto está dividido em quatro capítulos. Num primeiro momento são apresentadas as principais técnicas de reprodução humana assistida e suas principais indicações. O capítulo seguinte aborda especificamente a Doação Compartilhada de Oócitos, já apresentando algumas reflexões importantes sobre a temática. Posteriormente é analisada a hipótese de haver comercialização na Doação Compartilhada de Óocitos. Por fim, o último capítulo aborda a aplicação do princípio da beneficência à problemática analisada, abordando, ainda, reflexões filosóficas sobre a temática. As considerações finais são trabalhadas no último capítulo.

A hipótese inicial da pesquisa é no sentido de demonstrar a importância de se refletir sobre o tipo de relação negocial existente na Doação Compartilhada de Óocitos e as consequências daí advindas.

\section{DAS TÉCNICAS DE REPRODUÇÃO HUMANA ASSISTIDA}

A tecnologia vem possibilitando soluções para questões em diversas áreas do conhecimento, inclusive quando se fala em manutenção e restauração da saúde. Nesse sentido, problemas presentes na vida de casais podem ser solucionados com ajuda da medicina aliada à tecnologia.

Assim, casais impossibilitados de engravidar devido à infertilidade ${ }^{112}$, esterilidade $^{113}$ ou doenças hereditárias dominantes ${ }^{114}$, atualmente, possuem mais chances de terem o desejado bebê com a chamada reprodução humana assistida (RA) que consiste no:

Conjunto de técnicas, utilizadas por médicos especializados, que tem como principal objetivo tentar viabilizar a gestação em mulheres com dificuldades de engravidar. Muitas vezes essas dificuldades, até mesmo a infertilidade do casal ou um de seus membros, podem trazer sérios prejuízos ao relacionamento conjugal. (CORRÊA; COSTA, s/d).

Dentre as técnicas de reprodução assistida serão abordadas as mais utilizadas, quais sejam, Relação Sexual Programada (Coito Programado), Inseminação Artificial Intrauterina, Indução da Ovulação, Fertilização In Vitro (FIV) por Injeção Intracitoplasmática de Espermatozóide (ICSI), Doação Temporária de Útero e Doação Compartilhada de Oócitos, sendo que esta será objeto de estudo do próximo capítulo:

\footnotetext{
112 "Dificuldade de um casal obter gravidez no período de um ano tendo relações sexuais sem uso de nenhuma forma de anticoncepção". (MINISTÉRIO DA SAÚDE, 2015).

${ }^{113}$ Incapacidade de ter filhos.

${ }^{114}$ Doença hereditária é aquela cujo mecanismo de transmissão de ascendentes para descendentes é mediado pela configuração cromossômica de um ou de ambos os progenitores. A característica dominante depende de um determinismo genético cromossômico. Quando, no indivíduo diploide (organização em pares dos cromossomos), o fenótipo (variante das características particulares de um indivíduo) determinado por um alelo (cada uma das diferentes variantes) se manifesta, diz-se que esse alelo é dominante. Nesse caso, o alelo não precisa estar em dupla para se manifestar (LOPES, 2008, p. 247-249).
} 


\section{a. Relação Sexual Programada (Coito Programado)}

Na relação sexual programada há o acompanhamento do ciclo ovulatório da mulher, por meio de ultrassom, a fim de identificar quando ocorrerá a ovulação, caso esta não ocorra, induz-se a ovulação com o emprego de medicamentos. A finalidade do coito programado é orientar o casal sobre o dia certo para se ter a relação sexual. (BUTTROS, 2017).

\section{b. Inseminação Artificial Intrauterina}

A inseminação artificial intrauterina objetiva facilitar o encontro do óvulo com os espermatozoides. O sêmen é preparado em laboratório, na busca de espermatozoides mais rápidos a serem colocados dentro do útero através de um cateter ${ }^{115}$ de plástico, uma vez que é longo o caminho que os espermatozoides percorrem. Estudos demonstram que para um bom resultado da inseminação é importante induzir, com a utilização de medicamentos, a ovulação ${ }^{116}$. Desse modo, por meio de ultrassom, as fases crescimento, amadurecimento e liberação do óvulo, são acompanhadas, a fim de ajustar a fase de ovulação com a inseminação (CAETANO, 2000, p.47-49).

c. Indução da Ovulação

A indução da ovulação é o tratamento base de todas as técnicas de reprodução assistida, pela qual a mulher toma "medicamentos para estimular os ovários a produzir mais de um óvulo por ciclo". A depender da técnica empregada a indução terá uma maior ou menor quantidade de hormônios a serem utilizados, associados a outros remédios. Anteriormente à decisão e encaminhamento para a utilização de medicamentos faz-se um estudo completo do casal em relação ao organismo, no que tange à reprodução, para detectar se não haveria outro meio para se chegar a gravidez sem a medicamentação. (CALLUCCI, 2003, p.89).

\section{d. $\quad$ Fertilização in Vitro por Injeção Intracitoplasmática de Espermatozoide (Bebê de Proveta)}

$\mathrm{Na}$ fertilização in vitro os óvulos e os espermatozoides são coletados. Após a coleta, os espermatozoides serão estabilizados em uma solução Polivinilpirrolidona (PVP) ${ }^{117}$ e cada um deles será injetado em um oócito diferente. (FILHO, 1997, p.90). Estas células reprodutoras serão colocadas em uma incubadora, de modo a imitar as condições do útero. (BUSSAB, 2017).

Essa técnica apresenta complexidade devido às etapas que versam sobre o procedimento. Denomina-se injeção intracitoplasmática de espermatozoide, pois por meio do aparelho de microscopia o óvulo receberá o espermatozoide. (VIEIRA, 2016). Encerrada a verificação da situação em que se encontram os embriões, eles serão transferidos para a cavidade uterina ou para as trompas.

\section{e. Doação Temporária de Útero/Útero de Substituição}

\footnotetext{
115 Tubo plástico de calibre milimétrico e de comprimento variável.

116 Processo que ocorre quando as alterações hormonais estimulam um ovário a liberar um óvulo, o que viabiliza que este seja encontrado pelo espermatozoide.

${ }^{117}$ Composto químico solúvel em água.
} 
O casal nomeia uma mulher mediante um contrato, cujas cláusulas versam que esta emprestará o útero para a formação do bebê, e entregará a criança ao casal posteriormente ao nascimento. O contrato será homologado pelo juiz com o parecer do Conselho Federal de Medicina. Os óvulos inseminados com o sêmen, ambos do casal, formarão os embriões, pela técnica de fertilização in vitro, a serem transferidos para o útero emprestado. (OLIVEIRA, 2013).

$\mathrm{Na}$ atuação para a efetivação das técnicas, o Brasil possui Bancos de Células e Tecidos Germinativos espalhados pelo território, cujo funcionamento, tanto para estabelecimento de natureza pública quanto privada, é regulado pela ANVISA, objetivando a segurança e qualidade das células, tecidos germinativos e embriões. (AGÊNCIA NACIONAL DE VIGILÂNCIA SANITÁRIA, 2011).

Neste contexto, o levantamento realizado pela ANVISA contabilizou, com dados entregues de 146 Bancos de Células e Tecidos Germinativos, o total de 36.307 ciclos de fertilização in vitro realizados, ou seja, essa quantidade expressa o número de "procedimentos médicos nos quais a mulher é submetida à produção (estímulo ovariano) e retirada de oócitos para realizar a Reprodução Humana Assistida"; 134.580 embriões produzidos em laboratório dentro de um ciclo de fertilização, sendo que 68.891 desta produção foram transferidos ao útero da paciente por meio de procedimentos médicos apropriados. (AGÊNCIA NACIONAL DE VIGILÂNCIA SANITÁRIA, 2017, p.6-7).

Com uma breve explanação das técnicas, percebe-se que são muitos os métodos para contornar os problemas dos casais que optam por engravidar. Esses casais com dificuldade de ter filhos procuram, cada vez mais, pelas técnicas de reprodução assistida, por isso tornam-se relevantes as discussões relacionadas ao tema.

\section{DA DOAÇÃO COMPARTILHADA DE OÓCITOS}

A Doação Compartilhada de Oócitos não possui previsão legal, entretanto o Conselho Federal de Medicina, em sua colocação mais recente sobre o tema, estabeleceu a Resolução n. 2.168/17 (que adota as normas éticas para a utilização das técnicas de RA) cujos artigos abrangem o caráter da doação, a idade limite para a sua realização, entre outros aspectos concernentes a essa técnica de reprodução assistida.

A própria Resolução expressa que a Doação Compartilhada de Oócitos consiste na situação em que doadora e receptora possuem problemas de reprodução e decidem compartilhar o material biológico e os custos financeiros correspondentes a essa técnica de reprodução assistida. Assim, uma das exigências que se faz presente é a das doadoras e receptoras estarem em tratamento nas clínicas, em momento anterior à doação. (CONSELHO FEDERAL DE MEDICINA, 2017, VI, 9).

$\mathrm{O}$ requisito da exigência de que as mulheres estejam em tratamento levanta o primeiro questionamento: estaria a doadora apta a consentir livremente em relação à utilização de seus óvulos por 
outra mulher? A reflexão se faz necessária tendo em vista que a doadora depende da equipe médica responsável pelas técnicas, pelas quais procurou a clínica, para ter seu problema solucionado. (CORRÊA, 2000). Ademais, o fator "preço" também pode ser um agravante, visto que a receptora, ao concordar com a doação, divide os custos do tratamento com a doadora.

Profissionais da saúde ao submeterem seus pacientes a determinadas práticas devem colher suas assinaturas por meio do termo de consentimento livre e esclarecido, que consiste em explicação sobre os procedimentos, riscos, benefícios, desconfortos e direitos envolvidos na realização do método a ser empregado, objetivando uma decisão autônoma daquela pessoa que assinará o documento.

Essa decisão se dá pela escolha em prosseguir com o procedimento com base nas informações, constantes no documento escrito, referentes a todos os aspectos relacionados à realização do método buscado, de modo a evitar uma deliberação induzida por não haverem sido prestados os esclarecimentos devidos.

Dessa forma, de acordo com o que foi apresentado sobre o termo de consentimento, a mulher submetida ao tratamento na clínica tem a plena possibilidade de consentir livremente. A dependência pela equipe médica não retiraria o caráter de uma decisão tida como autônoma. Assim, a mulher optando pelo procedimento, mesmo se fator decisivo estiver associado à dependência médica, possui uma decisão consciente, visto que ela passou a conhecer todos os elementos para definir seu posicionamento.

Com relação à questão da divisão dos custos do tratamento, não nenhuma objeção, uma vez que há previsão na Resolução de tal hipótese, fato que será melhor trabalhado no capítulo seguinte.

Diante do exposto, salienta-se que a estimulação ovariana sem sucesso muitas vezes é associada à idade em que a mulher começa a ter relações sexuais a fim de engravidar. Essas mulheres ganharam espaço no mercado de trabalho, motivo pelo qual alteraram seus comportamentos. $\mathrm{O}$ estudo e estabilidade financeira são tidos como principais caminhos a serem percorridos por elas, o que resulta na realização da gestação em período posterior à realização daqueles objetivos. (CAVALCANTE, 2005).

A idade elevada configura uma preocupação obstétrica tendo em vista os resultados maternos e perinatais $^{118}$. Observa-se um declínio na fertilidade feminina a partir dos 35 anos em consequência do envelhecimento dos óvulos e dos ovários, uma vez que a mulher já nasce com todos os óvulos. Ademais, "quanto mais avançada a idade feminina, maior a exposição a fatores que podem comprometer a fertilidade, como Doenças Sexualmente Transmissíveis (DSTs), inflamação nas trompas, aparecimento de miomas ou endometriose". (COMUNICAÇÃO RCC, 2011).

Nesse sentido, Renato de Oliveira, ginecologista responsável pela área de reprodução humana da Criogênesis esclarece que:

\footnotetext{
${ }^{118}$ Referem-se ao período um pouco anterior ou posterior aos nascimentos.
} 
Ao nascer, a menina já perde $70 \%$ dos oócitos, que são os gametas femininos, resultando em, aproximadamente, dois milhões de gametas. Na menarca, ou seja, primeira menstruação, a mulher possui de 300 a 500 mil de oócitos. Aos 30 anos, estima-se que apenas 500 oócitos serão selecionados para serem ovulados. E, depois dos 35 anos, há uma queda importante tanto da quantidade quanto na qualidade dos oócitos maternos, que por possuírem a idade da mãe, ficam mais suscetíveis a alterações genéticas e erros na divisão celular quando fecundados. Assim, principalmente após os 38 anos, aumenta a probabilidade tanto de aborto quanto de nascimento de uma criança com alguma síndrome genética. (CRIO GÊNESIS, 2016).

Por conseguinte, as chances de uma mulher engravidar por meio da doação compartilhada de oócitos, aumentam, considerando que a receptora poderá adquirir oócitos de uma doadora detentora de células germinativas mais "jovens", uma vez que a idade limite estabelecida pela Resolução para que a mulher seja doadora é de 35 anos (já para que seja receptora, é de 50 anos, ressalvados casos especiais que devem ser analisados individualmente).

\section{DA HIPÓTESE DE HAVER COMERCIALIZAÇÃO NA TÉCNICA DA DOAÇÃO COMPARTILHADA DE OÓCITOS}

Na Doação Compartilhada de Óocitos é possível identificar duas relações entre os envolvidos. A primeira compreende cada uma das mulheres, em separado, e as clínicas, centros ou serviços aplicadores das técnicas de reprodução assistida; sendo a segunda relacionada às mulheres que recorrem a esses locais e optam pelo compartilhamento de óocitos (lembrando que, como já mencionado, doadora e receptora não podem conhecer a identidade uma da outra).

Analisando-se os custos que envolvem a doação, surge o questionamento se o procedimento em questão ensejaria em um contrato de compra e venda, caracterizando a comercialização.

Configura-se um contrato quando houver a presença, conjunta, dos elementos subjetivo e objetivo que se caracterizam, respectivamente, pelo acordo de vontade e pela relação ou pelo poder jurídico, "de natureza patrimonial, constituído, regulado ou extinto pelo mesmo consentimento". (BESSONE, 1997, p.41).

O Código Civil nos contratos em espécie expõe o seguinte: "pelo contrato de compra e venda, um dos contratantes se obriga a transferir o domínio de certa coisa, e o outro, a pagar-lhe certo preço em dinheiro." (CÉSPEDES, 2017, p. 190).

Compreendem-se como elementos da compra e venda, a coisa, o preço e o consentimento. Segundo Carlos Gonçalves, deve-se levar em consideração quanto aos elementos essenciais a "natureza específica, a par dos elementos constitutivos em geral, comum a todos eles, como requisitos de existência e validade". (GONÇALVES, 2007, p. 195-196) 
Em complementação aos requisitos acima abordados, os elementos constitutivos do negócio jurídico tornam-se possíveis por meio de dois planos - eficácia e validade (GONÇALVES, 2013, p. 348, $358,360-362)$ :

a. A eficácia reflete a norma jurídica se presentes os elementos estruturais;

b. A validade relaciona-se aos requisitos do negócio jurídico que são:

b.1. Agente capaz: a pessoa pode exercer, por si só, os atos da vida civil, assim o indivíduo está sujeito a direitos e obrigações na ordem civil;

b.2. Objeto lícito, possível, determinado ou determinável: será lícito o objeto que não for contra a lei, a moral ou os bons costumes; será impossível o objeto quando o ordenamento jurídico, de forma expressa, proibir negócios envolvendo certos bens; será determinado quando especificado e determinável ao não possuir a especificação que será atribuída posteriormente;

b.3. Forma: corresponde ao meio pela qual a vontade é revelada.

Tendo em vista os elementos para a configuração do contrato de compra e venda, estaria ausente o elemento preço, pois "inexiste a equivalência entre as prestações, até mesmo porque não há como se avaliar pecuniariamente o ato da doadora. " (NAVES; SÁ, 2015b).

Retornando à colocação sobre a existência de relações negociais entre as pessoas envolvidas e o disposto sobre o preço, na relação entre a mulher e a clínica de reprodução humana, haveria um contrato de compra e venda, visto que o local objetiva custear o procedimento, em contrapartida, na relação entre as mulheres, não haveria o contrato pela ausência do preço, portanto, não há que se falar em comercialização.

Ademais, a Lei 9.434 (BRASIL, 1997) que veda a comercialização de tecidos, órgãos e partes do corpo humano não compreende, para efeitos de sua aplicação, a gratuidade ou não acerca do óvulo, então haveria a possibilidade do comércio de óvulos e gametas.

Por outro lado, a Resolução acerca da doação, veda o caráter lucrativo ou comercial do procedimento, o que não implica, em tese, em um problema quanto a comercialização, posto que a Resolução é um ato legislativo que produz efeitos internos, não estando sujeita à promulgação ou ao controle preventivo da constitucionalidade, salvo as provenientes de acordos internacionais.

Apesar de a Resolução ser apenas uma orientação, por não possuir força de lei, o Cadastro Nacional de Doadoras de Óvulos afirma cumprir as normas impostas pela Resolução CFM n. 2.168/2017 e apresenta no "corpo" de seu site a vedação ao caráter lucrativo ou comercial, sendo que tal entendimento prevalece no Brasil.

Entretanto, quando a Resolução permite a divisão dos custos do tratamento, pode-se levantar a hipótese de haver aí um contrato de compra e venda de óocitos. Apesar de, em um primeiro momento 
parecer haver tal relação negocial, isso não se configura na teoria ${ }^{119}$. O primeiro óbice é a questão do anonimato da doadora e da receptora, o que impediria que o contrato fosse tecnicamente possível. O segundo óbice é a própria ausência de precificação do "produto" (óocitos), por ser explicitamente vedada tal prática. Por fim, ressalta-se que a divisão de custos seria, na verdade, uma divisão das benesses do tratamento, que possui um valor elevado e traz muito desconforto físico para as pacientes, por ser um tratamento invasivo e que exige uma dosagem hormonal elevada.

Apresentadas as principais reflexões sobre a temática, resta analisar a aplicação do princípio da beneficência nas situações de Doação Compartilhada de Óocitos.

\section{DO PRINCÍPIO DA BENEFICÊNCIA NA DOAÇÃO COMPARTILHADA DE OÓCITOS}

O termo bioética ganha notoriedade no âmbito da medicina e das ciências biológicas com os seguintes acontecimentos que impulsionaram o estudo da ética interligada à vida (FABRIZ, 2003, p.82-84):

a. condenação de médicos alemães, pelo Tribunal de Nuremberg, por perpetrarem horrorizardes experimentais em seres humanos na época nazifascista;

b. a publicação de critérios de seleção dos candidatos para submeterem ao procedimento da hemodiálise renal, pela revista Life Magazine, em 1962;

c. o pedido dos pais da jovem, Karen Ann Quinley, para desligamento do equipamento respiratório, uma vez que receberem a notícia de que o estado de coma de sua filha, devido ao uso de álcool e barbitúricos ${ }^{120}$, era irreversível. Então, a Suprema Corte do Estado de Nova Jersey julgou procedente o pedido, reconhecendo o direito à morte digna. Mas para se chegar a esta conclusão foi necessária a verificação do prognóstico pelo Comitê de Ética, o que até então não havia no hospital onde a paciente estava. Essa situação foi precedente para instituição de Comitês de Ética em vários hospitais norteamericanos;

d. a criação do projeto Genoma Humano para esclarecer, mapear e sequenciar a estrutura do DNA humano.

Diante desses eventos, "a bioética representa um estudo acerca da conduta humana no campo da vida e da saúde humana e do perigo da interferência nesse campo pelos avanços das pesquisas biomédicas e tecnocientíficas". (FABRIZ, 2003, p.75).

\footnotetext{
${ }^{119} \mathrm{O}$ trabalho não teve como propósito analisar a existência de possíveis situações reais de compra e venda de óocitos. Apesar disso, há relatos de mulheres brasileiras que procuram sites internacionais como forma de burlar esse impedimento e terem suas necessidades atendidas em países exteriores. (COSTAS, 2012).

${ }^{120}$ Os barbitúricos são a combinação de uréia e ácido malônico. A depender de sua fórmula e dosagem, podem apresentar um efeito sedativo, hipnótico, anticonvulsivo ou anestésico.
} 
Dessa maneira, a análise do princípio da beneficência insere-se no estudo da Bioética sob os pontos de vista científico, biológico e médico, relacionando-se essa disciplina com a verificação da "licitude da intervenção do homem sobre o homem". (SGRECCIA, 2009, p.51).

A UNESCO, em 1997, com a adoção da Declaração Universal sobre o Genoma Humano e os Direitos Humanos: da Teoria à Prática, evidencia a preocupação no tocante à beneficência: "Pesquisa, tratamento ou diagnóstico que afeta o genoma do indivíduo deve ser realizado somente após avaliação rigorosa e prévia dos riscos e benefícios potenciais a este respeito e de acordo com qualquer outra exigência de legislação nacional” (UNESCO, 2001, article 5, "a”, tradução livre). "21",

Assim sendo, o princípio da beneficência "impõe ao profissional da saúde ou ao biólogo o dever de dirigir esforços no sentido de beneficiar o ser". Outrossim, a beneficência deve reger a conduta médica, estando esta sujeita ao consentimento do paciente. (NAVES; SÁ, 2015a, p. 35-36).

Para esclarecer o princípio da beneficência aplicada à Doação Compartilhada de Oócitos faz-se necessária a explanação das duas linhas éticas quais sejam, a ética teleológica e a ética deontológica. Apesar de distintos os conceitos, ambas se integram, somando as questões valorativas e normativas.

Aristóteles, filósofo grego, foi um dos pensadores cuja filosofia adentra na esfera teleológica. O caráter teleológico é aquele em que o conceito central/primordial é a noção de Bem. Destarte, essa ética se divide em duas vertentes: consequencialistas, as quais consideram o valor moral de uma ação a depender das consequências geradas e; eudaimônicas, consistem em "uma vida que vale a pena, uma vida lograda, ou, como dirão os autores contemporâneos, 'boa vida' ou 'florescimento'.”. (PEREIRA, 2017, p.37).

Em contrapartida, Imannuel Kant, filósofo prussiano, foi um dos representantes na esfera deontológica. O caráter deontológico corresponde ao estudo do dever. Por conseguinte, todos os acontecimentos devem ser julgados devido ao homem assumir o estado de sujeito da razão.

\begin{abstract}
Não serão, então, os desejos e inclinações dados naturalmente, não serão os interesses contingentes e históricos que determinarão o que é humano [...] no mundo há muitas coisas boas, ações e relações, que são boas para algo, mas só a boa vontade é boa vontade o bem incondicionado. Este bem não é o resultado de qualquer ação, não é uma vontade de bom coração ou disposta a ajudar, mas a vontade que o homem produziu ao constituir-se como senhor de si, como legislador de si mesmo. Boa vontade é unicamente aquela que se determina pela sua própria lei, a lei da razão. (F., 2001, p. 20).
\end{abstract}

Consequentemente, a Doação Compartilhada de Oócitos, no sentido teleológico insere-se por meio da felicidade das mulheres que passarão pelo procedimento, em poder contribuir uma com a outra, apesar de não conhecerem a identidade daquela com quem compartilham o material biológico e os custos financeiros. No sentido deontológico, adentra ao assunto do consentimento livre e esclarecido, já elucidado em capítulo

\footnotetext{
121 "Research, treatment or diagnosis affecting an individual's genome shall be undertaken only after rigorous and prior assessment of the potential risks and benefits pertaining thereto and in accordance with any other requirement of national law" (UNESCO, 2001, article 5, "a").
} 
anterior, à conformidade do procedimento com a lei, bem como do compartilhamento das benesses do tratamento.

\section{CONSIDERAÇÕES FINAIS}

As técnicas de reprodução humana assistida datam longo período, desde seu início, com o nascimento do primeiro bebê por intermédio da fertilização in vitro. Muito se descobriu desde então. Hoje, as mulheres contam com uma variedade de artifícios médicos promovedores da gestação.

A Doação Compartilhada de Oócitos originou-se pela observação e levantamento de inúmeras mulheres, na condição de doadoras de óvulos ou na conjuntura de insuficiência de condição para custear o tratamento, ocasião em que houve a união de duas vontades convergentes ao mesmo resultado, o de engravidar.

Posteriormente a sua criação, a Resolução do Conselho Federal de Medicina objetivou ser um caminho alternativo para a inércia do legislador em relação à Doação Compartilhada de Oócitos, tendo em vista a necessidade de estabelecer critérios acerca do tema.

Uma das disposições estabelecidas foi a vedação da comercialização. Nesse sentido, o que se buscou reforçar foi o aspecto do compartilhamento das benesses do tratamento entre as mulheres, e não uma relação negocial de compra e venda de ócitos. Na doação compartilhada a doadora compartilha seu material genético e a receptora, por outro lado, compartilha os custos do tratamento da doadora.

A única relação negocial existente, assim, seria entre a mulher (doadora e receptora) e a própria clínica de reprodução. Assim, todas as obrigações daí decorrentes nascem dessa relação. É importante ressaltar, ainda, que a clínica também atua como intermediária entre doadora e receptora que, como bem demonstrado, não podem conhecer da identidade uma das outras.

Por tais motivos, tendo em conta a necessidade de proteção às pacientes, a bioética surge com a finalidade de nortear atuações médicas, por meio de seus princípios, sobretudo os da beneficência e da autonomia, de forma a possibilitar o melhor tratamento às clientes nas peculiaridades de cada situação.

\section{REFERÊNCIAS}

AGÊNCIA NACIONAL DE VIGILÂNCIA SANITÁRIA. RDC No 23, de 27 maio de 2011. Dispõe sobre o regulamento técnico para o funcionamento dos Bancos de Células e Tecidos Germinativos e dá outras providências. Disponível em: <file://C:/Users/Convidado/Downloads/resoluo\%20rdc\%20n\%2023\%202011\%20$\% 20$ banco $\% 20$ de $\% 20$ clulas $\% 20 \mathrm{e} \% 20$ tecidos $\% 20$ germinativos $\% 20 \mathrm{bctg} \% 20$ republicada.pdf $>$. Acesso em: 17 jun. 2018. 
AGÊNCIA NACIONAL DE VIGILÂNCIA SANITÁRIA. 11 $^{\circ}$ Relatório do Sistema Nacional de Produção de Embriões - SisEmbrio. 2017. Disponível em: <http://portal.anvisa.gov.br/documents/33840/330551/11 +Relatório+Sisembrio.pdf/e82275b0-e69a-486d8aab-fc6ab7bfffc3>. Acesso em: 16 jun. 2018.

BESSONE, Darcy. Do Contrato: Teoria Geral. São Paulo: Saraiva, 1997.

BRASIL. Lei n⿳9.434, 4 de fevereiro de 1997. Dispõe sobre a remoção de órgãos, tecidos e partes do corpo humano para fins de transplante e tratamento e dá outras providências. Disponível em: <http://www.planalto.gov.br/CCIVil_03/LEIS/L9434.htm>. Acesso em: 9 abr. 2018.

BUTTROS, Davi. Coito Programado. 31 jan. 2017. (2m29s). Disponível em: <https://www.youtube.com/watch?v=fzjJRv3ulvE>. Acesso em: 20 jun. 2018.

BUSSAB, Augusto. FIV x Inseminação Artificial. 21 dez de 2017. (7m28s). Disponível em: <https://www.youtube.com/watch?v=adJE5HRfXZE>. Acesso em: 19 jun. 2018.

CADASTRO NACIONAL DE DOADORAS DE ÓVULOS. Leis brasileiras de ovodoação: o que a lei diz. Disponível em: <https://cndo.com.br/leis-brasileiras-de-ovodoacao>. Acesso em: 15 ago. 2018.

CAETANO, João Pedro Junqueira; MARINHO, Ricardo; MORAES, Leonardo Meyer de. Infertilidade e Concepção Assistida: Um Guia para o Casal. Rio de Janeiro: MEDSI, 2000.

CALLUCCI, Cláudia. Por que a gravidez não vem: Respostas objetivas e didáticas às principais dúvidas sobre fertilidade. São Paulo: Editora Atheneu, 2003.

CAVALCANTE, E. et al. Resultados das técnicas de reprodução assistida em mulheres doadoras de oócitos no ciclo de tratamento. Rev Bras Ginecol Obstet. 2005. Disponível em: <http://www.scielo.br/pdf/\%0D/rbgo/v27n11/28707.pdf> . Acesso em: 25 jun. 2018.

CÉSPEDES, Lívia (Coord.). Vade mecum acadêmico de direito Saraiva. 24. ed. atual. e ampl. São Paulo: Saraiva, 2017.

COMUNICAÇÃO RCC. Por que as mulheres têm mais dificuldade em engravidar depois dos 40? 1 jul. 2011. Radiologia Clínica de Campinas. Disponível em:

<http://www.radiologiaclinicadecampinas.com.br/blog/?p=225>. Acesso em: 25 jun. 2018.

CONSELHO FEDERAL DE MEDICINA. Resolução n. 2.168, de 10 de novembro de 2017. Adota as normas éticas para a utilização das técnicas de reprodução assistida - sempre em defesa do aperfeiçoamento das práticas e da observância aos princípios éticos e bioéticos que ajudam a trazer maior segurança e eficácia a tratamentos e procedimentos médicos -, tornando-se o dispositivo deontológico a ser seguido pelos médicos brasileiros e revogando a Resolução CFM $\mathrm{n}^{\circ}$ 2.121, publicada no D.O.U. de 24 de setembro de 2015, Seção I, p. 117. Disponível em: <https://sistemas.cfm.org.br/normas/visualizar/resolucoes/BR/2017/2168>. Acesso em: 5 abr. 2018.

CORRÊA, Marilena Cordeiro Dias Villela; COSTA, Cristiano. Reprodução Assistida. Disponível em: <http://www.ghente.org/temas/reproducao/index.htm>. Acesso em: 19 jun. 2018.

CORRÊA, Marilena V. Novas tecnologias reprodutivas: doação de óvulos. O que pode ser novo nesse campo? Cadernos de saude pública. Jul.-set. de 2000. Disponível em: 
<https://www.scielosp.org/scielo.php?pid=S0102-311X2000000300036\&script=sci_abstract\&tlng=es > Acesso em: 23 jun. 2018.

COSTAS, Ruth. Brasileiras vendem óvulos e barrigas de aluguel a estrangeiros na internet. BBC Brasil. 2012. Disponível em:

<https://www.bbc.com/portuguese/noticias/2012/09/120824_turismo_reproducao_mundo_ru.shtml>. Acesso em: 29 jun. 2018.

CRIO GÊNESIS. Gravidez tardia é possível, mas requer cuidados. 2016. Disponível em: $<$ https://criogenesis.com.br/2016/12/23/gravidez-tardia-e-possivel-mas-requer-cuidados/>. Acesso em: 25 jul. 2018.

F.; Javier Herrero. A Ética de Kant. Síntese. Revista de Filosofia. 2001. v. 28. n. 90. Disponível em: <http://faje.edu.br/periodicos/index.php/Sintese/article/view/563/987>. Acesso em: 29 jun. 2018.

FABRIZ, Daury Cesar. Bioétoca e Direitos Fundamentais: A Bioconstituição como Paradigma do Biodireito. Belo Horizonte: Mandamentos, 2003.

FILHO, Alberto Soares Pereira. (Coord.). Infertilidade Conjugal: Manual de Orientação. São Paulo: FEBRASGO, 1997.

G1. Nobel de Medicina vai para criador de método de fertilização in vitro: Robert Edwards concebeu técnica em 1978, depois de 20 anos de pesquisa. Até hoje, 4 milhões de pessoas já nasceram após a pesquisa do britânico. 4 out. 2010. Disponível em: <http://g1.globo.com/ciencia-e-saude/noticia/2010/10/nobel-demedicina-vai-para-criador-de-metodo-de-fertilizacao-vitro.html>. Acesso em: 20 jun. 2018.

GONÇALVES, Carlos Roberto. Direito Civil Brasileiro: Contratos e Atos Unilaterais. 4. ed. v. 3. São Paulo: Saraiva, 2007.

GONÇALVES, Carlos Roberto. Direito Civil Brasileiro: Parte Geral. 11. ed. v. 1. São Paulo: Saraiva, 2013.

GUSTIN, Miracy Barbosa de Sousa; DIAS, Maria Tereza Fonseca. (Re)pensando a pesquisa jurídica: teoria e prática. 3. ed. Belo Horizonte: Del Rey, 2010.

LOPES, Sônia. Bio. 2. ed. v. único. São Paulo: Saraiva, 2008.

MINISTÉRIO DA SAÚDE. Infertilidade feminina. Biblioteca Virtual em Saúde. 23 fev. 2015. Disponível em: <http://bvsms.saude.gov.br/dicas-em-saude/151-infertilidade-feminina>. Acesso em: 18 jun. 2018.

NAVES, Bruno Torquato de Oliveira. SÁ, Maria de Fátima Freire. Manual de Biodireito. 3. ed. Revista atualizada e ampliada. Belo Horizonte: Del Rey, 2015a.

NAVES, Bruno Torquato de Oliveira Naves; SÁ, Maria de Fátima Freire de. Panorama bioético e jurídico da reprodução humana assistida no Brasil. Revista Bioética y Derecho, Barcelona, n. 34, 2015 b. Disponível em: <http://scielo.isciii.es/scielo.php?script=sci_arttext\&pid=S1886-58872015000200007>. Acesso em: 8 abr. 2018.

OLIVEIRA, Flávio Garcia de. Barriga de Aluguel. 11 abr. 2013. (2m31s). Disponível em: <https://www.youtube.com/watch?v=YrlkwosDiiM>. Acesso em: 20 jun. 2018. 
PEREIRA, Rafael Rodrigues. Dois Tipos de Ética Teleológica. Cadernos de Ética e Filosofia Política. 2017. Disponível em: <https://www.revistas.usp.br/cefp/article/download/138745/134079>. Acesso em: 28 jun. 2018.

SGRECCIA, Elio. Manual de Bioética: Fundamentos e Ética Biomédica. v. 1. São Paulo: Edições Loyola, 2009.

UNESCO. The Universal Declaration on the Human Genome and Human Rights: from theory to practice. 2001. Disponível em: <http://unesdoc.unesco.org/images/0012/001229/122990eo.pdf>. Acesso em: 26 jun. 2018.

VIEIRA, Oilton Liberati. Dr. Oilton Liberati Vieira fala sobre Fertilização In Vitro, ICSI e Inseminação Artificial. 19 mai. 2016. (6m37s). Disponível em: <https://www.youtube.com/watch?v=xMYJwORMGIs\&t=2s>. Acesso em: 20 jun. 2018.

WITKER, Jorge. Como elaborar una tesis en derecho: pautas metodológicas y técnicas para el estudiante o investigador del derecho. Madrid: Civitas, 1985. 


\section{INSTRUÇÕES PARA PUBLICAÇÃO DE ARTIGOS NA REVISTA}

A "Dom Helder Revista de Direito" é uma publicação quadrimestral, integralmente eletrônica e de acesso gratuito, que publica artigos originais de pesquisadores graduandos e/ou detentores das titulações subsequentes no Direito e áreas afins, desde que relacionados à linha editorial "Justiça, Estado e Cidadania nas Sociedades Contemporâneas". Traduções somente serão aceitas caso o texto seja inédito no Brasil e o tradutor figure como coautor do texto. A "Dom Helder Revista de Direito" não cobra taxas de submissão de artigo ou taxas de processamento de artigo.

Os textos devem ser submetidos gratuitamente na página eletrônica da Revista após o cadastro como "AUTOR"

(http://www.domhelder.edu.br/revista/index.php/dhrevistadedireito/user/register) seguindo-se os passos de submissão. Em caso de dificuldades, enviar e-mail para: editorasecretaria@editoradomhelder.com.br

Informações sobre formatação, apresentação gráfica e exigências para os artigos, processo de avaliação, preenchimento dos metadados da submissão, entre outros, estão disponíveis no site http://www.domhelder.edu.br/revista/index.php/dhrevistadedireito/about/submissions\#authorGuidelines 